\title{
Calorie restriction and its impact on gut microbial composition and global metabolism
}

\author{
Xiaojiao Zheng ${ }^{1}$, Shouli Wang ${ }^{1}$, Wei Jia $(\bowtie)^{1,2}$ \\ ${ }^{1}$ Shanghai Key Laboratory of Diabetes Mellitus and Center for Translational Medicine, Shanghai Jiao Tong University Affiliated Sixth \\ People's Hospital, Shanghai 200233, China; ${ }^{2}$ University of Hawaii Cancer Center, Honolulu, HI 96813, USA
}

(C) The Author(s) 2018 This article is published with open access at link.springer.com and journal.hep.com.cn

\begin{abstract}
Calorie restriction (CR) is a dietary regimen that reduces calorie intake without incurring malnutrition or a reduction in essential nutrients. It has long been recognized as a natural strategy for promoting health, extending longevity, and prevents the development of metabolic and age-related diseases. In the present review, we focus on the general effect of CR on gut microbiota composition and global metabolism. We also propose mechanisms for its beneficial effect. Results showed that probiotic and butyrate-producing microbes increased their relative abundance, whereas proinflammatory strains exhibited suppressed relative abundance following CR. Analyses of the gut microbial and host metabolisms revealed that most host microbial co-metabolites were changed due to CR. Examples of dramatic CR-induced changes in host metabolism included a decrease in the rate of lipid biosynthesis and an increase in the rates of fatty acid catabolism, $\beta$-oxidation, glycogenolysis, and gluconeogenesis. The observed phenotypes and the further verification of the direct link between gut microbiota and metabolome may benefit patients that are at risk for developing metabolic disease. Thus, improved gut microbiota composition and metabolome are potential biomarkers for determining the effectiveness of dietary interventions for age-related and metabolic diseases.
\end{abstract}

Keywords caloric restriction; gut microbiota; metabolome

\section{Introduction}

Calorie restriction (CR), also called energy restriction, is a dietary regimen that reduces calorie intake without incurring malnutrition or reduction in essential nutrients. It has been recognized as a health-promoting strategy for a long time and shown to oppose age-related physiological and pathological changes, thereby extending longevity [13]. The roles of $\mathrm{CR}$ at the cellular and molecular levels have been identified in many studies; for instance, CR enhances cellular protection, and energy metabolism along with reduction of both inflammation and oxidative damage [4-6]. Thus, CR reduces mortality in mammals due to causes that are age-related or pathological causes, including diabetes, cancer, cardiovascular disease, and brain atrophy [1,7]. CR with its health-beneficial and lifespanextending effects has been applied and studied in such diverse species as fish, hamsters, mice, rats, and dogs

Received December 23, 2017; accepted September 27, 2018

Correspondence: Wei Jia, WJia@cc.hawaii.edu
[3,8-12]. Likewise, CR-induced beneficial effects have been observed in nonhuman primates and humans [13-16]. Recently, knowledge of gut microbiota and metabolic changes that result from CR has substantially increased.

Humans are considered superorganisms because diverse and dense microbiota populations colonize their gastrointestinal tracts $[8,17,18]$. The gut microbiota is considered a separate metabolic organ of the host because of its ability to modulate host nutrition, metabolism, and immunity [19]. The composition of gut microbiota is shaped mainly by diet [20]. Substantial evidence of dramatic diet-induced changes in microbiota composition resulting from fasting, use of laxatives, and low fat dietary intervention has been obtained; these changes counteract metabolic damages associated with obesity and high-fat diet [21]. Thus, these CR-induced alterations of the intestinal microbiota suggested that animals can establish a balanced gut microbiota composition via $\mathrm{CR}$, providing health advantages to the host.

Identifying the biochemical alterations related to different diets provide valuable insights into the 
associations between metabolism and phenotypes [22-26]. Global metabolomics captures system end point responses to these biological perturbations by measuring the chemical compositions of biological samples, such as biofluids and tissues. Studies have provided comprehensive information on the metabolic pathways and networks altered through $\mathrm{CR}$ intervention. These studies were important for uncovering the molecular mechanism of $\mathrm{CR}$. This review aims to highlight studies that address the relationships between the gut microbiota and the metabolic changes that occur with CR.

\section{CR and gut microbiota}

The mammalian gastrointestinal tract harbors a complex community of over 100 trillion microbial cells that can influence host physiology, nutrition, metabolism, and immune function. The dysbiosis of gut microbiota has been proven to be associated with several intestinal diseases, such as inflammatory bowel disease and colorectal cancer, as well as some systematic diseases such as diabetes and neurological diseases. Several studies found that the composition of the gut microbiota can be greatly changed by restricting dietary intake, without significant alterations in their $\alpha$-diversity [21,27-29]. CR studies showed that the gut microbiota exerts more prominent effects than some diseases, such as viral infection [30], or physical exercise [3]. However, some reports refute these observations [31-33], stating that the effect of CR on the microbiota is minimal. Such discrepancies might have been due to the limitation of technology for gut microbiota analysis at the time of these studies, the short duration of the CR, or use of a small study population. Moreover, during a rapid growing phase such as that of a $7-16$ weeks old rat, the gut microbiota composition could be mainly ascribed to normal physiological changes. Therefore, perturbation of the abundant genera and families might not have been detected [21]. The advent of improved sequencing technology and well-designed study protocols have allowed new findings related to the impact of CR on gut microbiota composition to emerge.

Studies of the CR effect on gut microbiota have been performed in mouse and rat, as well as, human models. The diet restriction regimens utilized were $10 \%-40 \%$ calorie restricted based on either a normal or high fat diet for animal studies, or 700-1500 kcal/day/person for human studies. Most of these reported studies focused on either normal or obese models [3,21,27], whereas some were conducted on participants with a pathological condition such as non-alcoholic fatty liver disease (NAFLD) [28] or influenza [30].

Factors that might have influenced the CR impact on gut microbiota were dietary composition and age of models. One murine study [3] showed that most of the microbes responding to $30 \%$ restricted high fat diet $(60 \%$ fat, D12492, Research Diets) were not found in mice with $30 \%$ restricted normal diet (10\% fat, D12450B, Research Diets). Furthermore, the CR-induced microbiota alterations were different in mice of mid-life and late-life ages. Another human study [29] showed that enormous differences in intestinal microbial composition existed between lean vs. obese subjects and such differences were absent after longterm CR. Thus, CR intervention adjusted the gut microbiota composition of obese subjects to that of the lean subjects which were dramatically different before intervention. Firmicutes, Bacteroidetes, and Proteobacteria are the main phyla in the gut microbiota; however, results regarding CR-induced alterations in the relative abundances of these bacteria varied [27,30,34,35]. Some studies reported that dietary intervention reduced the Bacteroidetes population in favor of Firmicutes [34], whereas longterm (45 days) CR in obese subjects enriched Bacteroidetes and greatly reduced the Firmicutes:Bacteroidetes ratio [35]. The inconsistent results might be due to the variable diversity of the microbes present under a specific phylum, and dietary intervention may have led to remarkably relative alterations in low-level taxa without affecting the relative abundance of a major phylum.

The alterations of microbes in different levels of taxa from different studies are summarized in Fig. 1. Generally, CR treatment showed a substantial effect on the relative abundances of microbes belonging to the Clostridiales order, that is, a decrease in families, Eubacteriaceae, Lachnospiraceae, Peptostreptococcaceae, and Erysipelotrichaceae. It also led to decreased abundance in the Bacteroidales order, whereas certain family levels belonging to this order showed an increasing trend, for example, for the families, Porphyromonadaceae, Rikenellaceae, and Bacteroidaceae $[3,21,29]$. Notably, in some studies, the operational taxonomic units (OTUs; several hits $>97 \%$ sequence identity) were annotated to species levels, such as increased abundances of Clostridium saccharolyticum, Clostridium cluster XIVa, Eubacterium limosum, Eubacterium cellulosolvens, Anaerostipes hadrus, Blautia hydrogenotrophica, and Butyrivibrio fibrisolvens, and decreased abundances of Clostridium perfringens, Agathobacter rectalis, Ruminococcus gnavus, and Akkermansia muciniphila. The widely reported microbes or altered functions with CR intervention are summarized in detail in the following sections.

\section{Probiotic strains}

Studies have shown an overall increased relative abundance of probiotic microbes, such as Bifidobacterium spp. and Lactobacillus spp. in CR-treated mammals [3,21,35]. Increased relative abundance of probiotic strains may explain some of the benefits of CR given the acknowledged role of these genera in promoting intestinal 


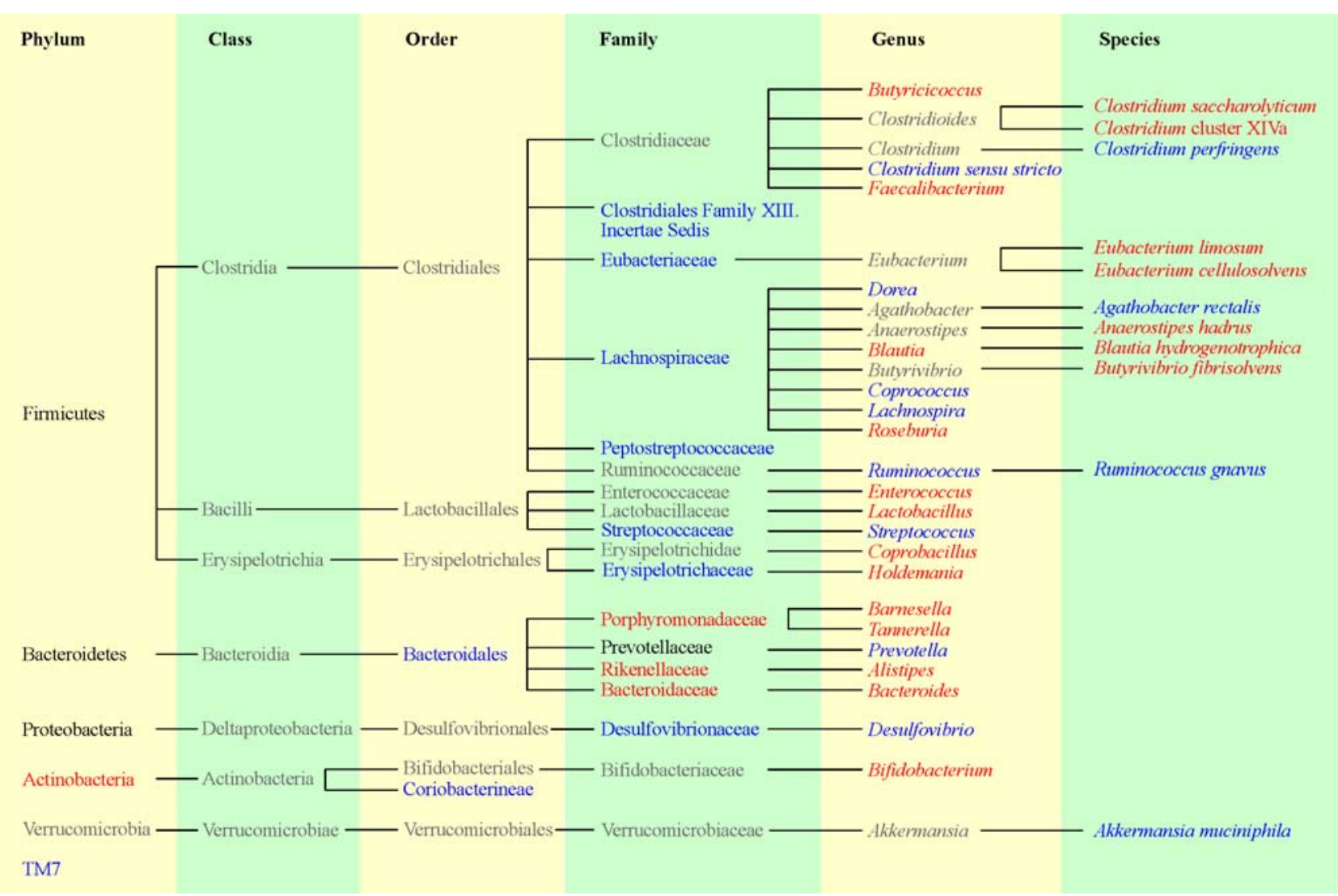

Fig. 1 Phylogenetic tree of all reported taxa. The abundance of taxa in red indicates increased abundance, blue indicates decreased abundance, and black indicates controversial alteration after CR intervention. The taxa in gray have not been reported in CR-related studies.

homeostasis by protecting against pathogen-induced gut barrier disruption, inhibiting pathogen adhesion to the intestinal wall, and reducing inflammatory cytokines [36,37]. The anti-inflammatory effect of Lactobacillus has been attributed to its surface antigens, which have structural or enzymatic functions. The increased abundances of Lactobacillus and Bifidobacterium in subjects under CR conditions correlated with decreases in body weight, total cholesterol, and triglycerides, and thus Lactobacillus spp. growth might be correlated to a dietdependent effect on lipid metabolism [21,36,38].

\section{Proinflammatory microbes}

Some harmful microbes inducing inflammation were inhibited with CR treatment. Desulfovibrionaceae, Streptococcaceae, and TM7 induced mild inflammation, which is positively associated with obesity, diabetes, and inflammatory mucosal processes in inflammatory bowel diseases [39-41]. After CR intervention (45-day 25\%restricted diet for mice and 28-day $800 \mathrm{kcal} /$ day diet for humans), the circulating lipopolysaccharide (LPS) binding protein (LBP) was reduced $[3,27]$. LBP is an important biomarker because it can bind to antigens produced by
Gram-positive bacteria; thus, the levels of LBP can reflect the antigen load in the circulation and the inflammatory response of the host [42]. With CR intervention, the antigen translocation from the gut to the blood might be considerably reduced due to the decreased abundance of Gram-positive bacteria $[39,43]$.

\section{Butyrate-producing microbes}

The growth of some butyrate-producing microbial strains, such as Coprobacillus, Holdemania, Eubacterium cellulosolvens, and Clostridium saccharolyticum was increased with CR [34]. Meanwhile, metagenomic data showed an increase in the metabolic capacity of Kyoto Encyclopedia of Genes and Genomes (KEGG) orthologs for butyrate fermentation after six months of very low carbohydrate diet in humans [34]. Butyrate is a short-chain fatty acid produced in the colon from fermented dietary fiber by gut microbiota. It is the main energy source of enterocytes and has been reported to have an anti-inflammatory effect by decreasing gut permeability [44]. Moreover, studies in murine models showed that the butyrate activation of intestinal glucagon-like peptide 1 (GLP-1) in enteroendocrine cells improved glycemic and insulin responses. In 
animals, butyrate-producing bacteria were reported to prevent diet-induced obesity [45] and alleviate NAFLD [46]. Some studies did not reveal significant differences in fecal butyrate content after CR intervention, which was explained by low prebiotic substrate levels in the diet $[34,47]$.

\section{Microbes with amino acid degradation function}

The metabolic functional changes in gut microbiota with CR intervention were also observed for bacteria associated with amino acid metabolism [28]. Increased lysine biosynthesis along with decreased phenylalanine and tryptophan synthesis and branched amino acid degradation were observed in the microbial metabolism of essential amino acids.

\section{CR and the global metabolome}

The global metabolome experiences a dramatic shift with $\mathrm{CR}$ intervention, as evidenced by metabolomics and transcript analyses in blood, urine, liver, and muscle (summarized in Table 1). The metabolism rapidly switched from lipid biosynthesis to fatty acid catabolism and stimulated downstream $\beta$-oxidation. In addition, $C R$ induced increased glycogenolysis and gluconeogenesis $[48,49]$. Most importantly, due to the $25 \%$ restricted dietary CR impact on the composition of gut microbiota, gut microbial metabolites were subsequently changed [8]. Important published metabolites and metabolic pathways are summarized in the following sections.

The global metabolism is more affected by diet composition than by energy supply alone. High dietary protein-to-carbohydrate ratio (low $\mathrm{P} / \mathrm{C}$ ratio $(7: 1)$ : $10 \%$ protein, $20 \%$ fat, and $70 \%$ carbohydrate; high $\mathrm{P} / \mathrm{C}$ ratio (1.3:1): $32 \%$ protein, $22 \%$ fat, and $46 \%$ carbohydrate) was positively associated with improvement in glycemic control [50]. In contrast, some studies suggested that increased protein intake may be ineffective and even detrimental to the maintenance of glucose homeostasis $[51,52]$ because increased levels of a single type of amino acid, that is, branched-chain amino acids (BCAA), produced from dietary protein were positively associated with insulin resistance [53,54]. Thus, the investigations of the $\mathrm{CR}$ effect with different diet compositions were inconsistent. Moreover, to evaluate the CR impact on the metabolism, not only caloric intake but also dietary macronutrient composition should be considered. The effect of CR varies among the metabolomes of various biofluids and tissues in the body. For instance, the urinary metabolome showed more fluctuations than the metabolomes of other biofluids, such as blood and saliva, indicating that urine samples were more sensitive to differences in diet than other body fluids [55]. Gender difference in metabolism alteration was observed in several studies [56,57]. Some other significant factors that have been investigated in the studies of CR and gut microbiota, such as age and baseline body weight, should also be included in studies of CR-induced changes in the metabolome.

\section{Host-microbial co-metabolites}

Metabolites with aromatic chemical structures, including indoles and benzoic acids, are main metabolites derived from biochemical degradation reactions involving Clostridium scatalogens, C. difficile, or certain Lactobacillus strains [58,59]. Such host microbial co-metabolites, including hippurate, p-cresol, dimethylglycine, phenylacetylglycine, and 4-hydroxyphenylacetic acid [8,22,60,61], were associated with gut microbial homeostasis that was modulated by diet $[62,63]$, although with observed differences in the alteration trend for diverse species and ages. Interestingly, increased levels of hippurate and dimethylgycine have been considered as age-induced biomarkers $[64,65]$. Their decreased levels in aged mammals resulting from a $40 \%$ restricted dietary CR treatment for 12 weeks may be the effect of modulated gut microbiota activity and improved nutrient digestibility, thereby providing supporting evidence for the beneficial effect of CR as anti-aging and causing increased longevity [66].

The CR intervention (20\% and $40 \%$ restricted diet for five days) was associated with elevated plasma levels of trimethylamine-N-oxide (TMAO) and reduced levels of trimethylamine (TMA), choline, and glycerophosphocholine [67]. Consistently, changes in the levels of aliphatic amines, including TMA, dimethylamine (DMA), and TMAO occurred in the urine [22]. Choline and methylamines (TMA and DMA) are metabolites derived from host-microbial interactions in the large intestine; choline can be metabolized by gut microbiota to DMA and TMA, and liver flavin monooxygenases ultimately metabolizes TMA to TMAO [68]. Therefore, changes in the levels of these compounds may indicate the relative abundance of methylamine-producing bacterial resulting from CRinduced changes in gut microbial community and activity.

\section{Lipids}

Alterations in blood lipoproteins has been widely shown in the studies of CR in mouse, rat, dog, and monkey models $[13,69-71]$, as well as in human clinical studies [14,72]. Changes in lipoproteins were manifested by the increase in blood and fecal high density lipoprotein (HDL) levels and reduction in low density lipoprotein (LDL) and very lowdensity lipoprotein (VLDL) levels [13,15,22,48,49,67]. Lower levels of LDL and VLDL are associated with a lowered risk of cardiovascular disease. Increasing the 
Table 1 CR related metabolites

\begin{tabular}{|c|c|c|c|}
\hline Metabolite types & Increased after CR & Decreased after CR & Inconsistent in the reports \\
\hline Host-microbial co-metabolites & Trimethylamine-N-oxide (TMAO) & $\begin{array}{l}\text { Hippurate, dimethylgycine, } \\
\text { trimethylamine (TMA) }\end{array}$ & $\begin{array}{l}\text { p-Cresol, phenylacetylglycine, } 4- \\
\text { hydroxyphenylacetic acid }\end{array}$ \\
\hline Lipoprotein & High density lipoprotein (HDL) & $\begin{array}{l}\text { Low density lipoprotein (LDL), very } \\
\text { low-density lipoprotein (VLDL) }\end{array}$ & \\
\hline $\begin{array}{l}\text { Glyceryl derivatives of lipids and } \\
\text { phospholipid choline }\end{array}$ & & $\begin{array}{l}\text { Choline, glycerophosphocholine, phos } \\
\text { phatidylcholine (PC) (18:0/20:4), } \\
\text { sphingomyelin (SM) (d18:0/16:1), } \\
\text { lysoPCs (C16:1, C16:0, C17:0, C18:2, } \\
\text { C18:1, C18:0, C20:4, C20:3, and } \\
\text { C22:6), diacylglycerol lipids, triacyl } \\
\text { glycerol lipids }\end{array}$ & \\
\hline Free fatty acids & & $\begin{array}{l}\text { n-6 polyunsaturated fatty acids, } \\
\text { palmitoleic acid (C16:1 n7), } \\
\text { heptadecenoic acid }(\mathrm{C} 17: 1 \mathrm{n} 7), \\
\gamma \text {-linolenic acid (C18:3 n6), } \\
\text { dihomo- } \gamma \text {-linolenic acid }\end{array}$ & $\begin{array}{l}\text { n-3 polyunsaturated fatty acids, mono } \\
\text { unsaturated fatty acids, saturated fatty } \\
\text { acids }\end{array}$ \\
\hline Ketone bodies & Acetoacetate, 3-hydroxybutyrate & & \\
\hline Bile acids & $\begin{array}{l}\text { Taurocholic acid, taurodeoxycholic } \\
\text { acid, deoxycholic acid, lithocholic } \\
\text { acid, } \omega \text {-muricholic acid, hyodeoxy } \\
\text { cholic acid }\end{array}$ & & \\
\hline Amino acids & $\begin{array}{l}\text { Glutamate, methionine, glutamine, } \\
\text { alanine }\end{array}$ & $\begin{array}{l}\text { Branched-chain amino acids, aromatic } \\
\text { amino acids }\end{array}$ & \\
\hline Others & Carnitine, gluconate & Pyruvate & \\
\hline
\end{tabular}

beneficial lipoprotein, HDL, has been closely related to attenuation of age-related disorders, metabolic dependent diseases, and cardiovascular diseases [73].

Glyceryl derivatives of lipids and phospholipid choline in liver [60] and serum [16,71] were significantly decreased after CR intervention, such as phosphatidylcholine (PC) (18:0/20:4), sphingomyelin (SM) (d18:0/16:1), and some lysoPCs (C16:1, C16:0, C17:0, C18:2, C18:1, $\mathrm{C} 18: 0, \mathrm{C} 20: 4, \mathrm{C} 20: 3$, and C22:6). Many of these compounds are involved in fatty acid catabolism, where triacylglycerols and phospholipids become hydrolyzed into non-esterified fatty acids, glycerol, and phosphocholine [67]. Such metabolic phenotypes were observed in some pathological models. In $\mathrm{db} / \mathrm{db}$ mice, reduction in the levels of most glycerolipids [diacylglycerol (DG) and TG] and related hepatic enzymes were observed [4]. In NAFLD, the CR-induced reduction of liver triglyceride (TG) may have contributed to the prevention of further hepatic alterations associated with insulin resistance (IR) [66]. Notably, the decreased level of SM (d18:0/16:1) was observed in overweight and obese women after eight weeks of CR intervention [74], whereas the proportion of plasma SM increased with age and was elevated in obese models $[75,76]$.

\section{Free fatty acids}

$\mathrm{CR}$ induced lipolysis in liver and adipose tissues and increased free fatty acid (FFA) release into circulation [4]. Enhanced autophagy induced by $\mathrm{CR}$ has been reported to increase lipolysis [77]. A controversial study showed that increased circulating fatty acids were positively associated with the development of IR. This result was explained by the fact that IR can be induced not only by FFA elevation but increased TG concentration [78]. Thus, the beneficial effect of CR in lipid metabolism may be due to decreased lipid storage and increased FFA in the circulation.

The CR-induced alteration in the levels of unsaturated fatty acids (UFA), polyunsaturated fatty acids (PUFA), monounsaturated fatty acids (MUFA), and saturated fatty acids (SFA) was inconsistent in several studies. In one murine study, CR increased MUFA levels in the liver, whereas PUFA levels decreased and no changes were observed in SFA levels [60]. In contrast, a clinical study [79] with obese subjects participating in a very low carbohydrate diet intervention presented with overall UFA levels, MUFA, and n-6 PUFAs that were decreased after dietary intervention, whereas SFAs and n-3 PUFA increased remarkably. Among these FFAs, four UFA levels were associated with improved metabolic markers, including palmitoleic acid (PA) (C16:1 n7), heptadecenoic acid (HA) (C17:1 n7), gamma-linolenic acid (GLA) (C18:3 n6) and dihomo-gamma-linolenic acid (DGLA). The consistent findings within these studies were lower PUFA levels, especially n-6 PUFA levels after CR intervention. The lower levels of n-6 PUFA were believed to be due to decreased inflammation and susceptibility to oxidation of the cellular membranes [60].

FFA related metabolites were also altered after CR intervention. FFA oxidation is the major fuel for ketone 
bodies and increased levels of the circulating ketone bodies, acetoacetate and 3-hydroxybutyrate were observed to be simultaneously elevated after CR and were high in the subjects with higher percentage of weight loss $[15,48,67,71,80]$. The serum level of carnitine was also increased with CR intervention (40\% dietary reduction for 12 weeks), greatly influencing fatty acid oxidation in vivo [70].

\section{Bile acids}

Bile acids (BAs) are downstream metabolites of cholesterol that are synthesized in the liver and secreted from the gall bladder into the intestine to aid lipid uptake by the intestine. Hepatic cholesterol accumulation can be alleviated through the production of bile acids [81]. Bile-acidactivated signaling pathways have become attractive therapeutic targets for metabolic disorders, such as obesity, type 2 diabetes, hypertriglyceridemia, and atherosclerosis, as well as other associated chronic diseases, such as nonalcoholic steatohepatitis $[82,83]$. The results have shown that a $40 \%$ CR increased the BA pool size (162\%) and total BAs in gallbladder, small intestinal contents, and serum, with contributions mainly from taurocholic acid (TCA) and some secondary BAs, such as taurodeoxycholic acid, deoxycholic acid, lithocholic acid (LCA), $\omega$-muricholic acid, and hyodeoxycholic acid [84-86]. Increases in these CR-induced BAs might be due to an increase in the rate of BA synthesis, conjugation in liver and intracellular transport in the ileum. This interpretation has been supported by the observation of increased expression of BA-synthetic (cytochrome P450 7a1 (Cyp7a1)), conjugating enzyme bile acid-CoA ligase (BAL) and the ileal BA binding protein (Ibabp) levels $[84,87]$. Hepatic bile acids can spill into the circulation and induce energy expenditure and glucose homeostasis $[87,88]$. Recent studies showed that bile acids play an important role in CR-induced longevity. One bile acid, LCA, was found to be an antiaging compound in yeast [89], where it influenced various longevity-related processes.

\section{Pyruvate and TCA cycle}

The levels of pyruvate in blood were significantly decreased after CR and fasting intervention [67,90]. Pyruvate kinase enzyme levels decreased in liver samples of mice with $30 \%$ restricted CR undergoing a step-down feeding regime [60]. Pyruvate is a key metabolic intermediate at the intersection between glycolysis and the TCA metabolic cycles [67]. CR promotes the TCA cycle and reduces glucose levels in contrast to metabolic phenotypes with high calorie intake; these phenotypes are characterized by elevated glucose levels and depleted levels of the TCA cycle intermediates, citrate, succinate, 2ketoglutarate, and cis-aconitate. Therefore, such metabolic characteristics of CR can potentially be used to prevent the development of insulin resistance, diabetes, and hyperglycemia [22].

\section{Pentose phosphate pathway (PPP)}

Increased levels of gluconate [13], which is a key metabolite of the PPP, and increased flux through the PPP, were observed under CR. This increase may be attributed to the $\mathrm{CR}$-induced upregulation of peroxisome proliferator-activated receptor $\alpha$ (PPAR $\alpha)$ expression [91]. Moreover, aging was associated with decline in the expression levels of PPP genes, although this association was counteracted by CR [91, 92]. The PPP is involved in the biosynthesis of nicotinamide adenine dinucleotide phosphate which is essential for various reductive biosynthetic processes, such as lipogenesis, cholesterol synthesis, and nucleotide production. The PPP also plays a substantial role in the regulation of $\beta$-oxidation in muscles, hepatic glucose output and systemic insulin sensitivity [93]. Thus, CR may upregulate PPAR $\alpha$ expression in skeletal muscles [91] and may increase insulin sensitivity in the liver and peripheral tissues by increasing glucose flux through the PPP and enhancing fatty acid synthesis [94].

\section{Amino acids}

The levels of some amino acids, such as phenylalanine and tyrosine, were considerably reduced after CR $[67,80,95,96]$, confirming that decreased levels of branched-chain and aromatic amino acids are significantly associated with weight loss and decreased homeostasis model assessment of insulin resistance (HOMA-IR) scores in overweight or obese subjects [97]. Studies of BCAA supplementation in humans [51] and animals [98] demonstrated that circulating branched chain and aromatic amino acids directly promoted IR through the obstruction of insulin signaling in skeletal muscles.

High levels of some amino acids were observed in CR animals, such as serine and glutamate, implying the maintenance of protein turnover rate after CR intervention [99]. These amino acids are known to be important for neurotransmitter biosynthesis and preservation of neurological function [100]. Plasma levels of the glucogenic amino acids, methionine, glutamine, alanine, and valine were also increased, promoting a CR-induced switch in energy metabolism toward energy conservation and gluconeogenesis [48].

\section{Prospective}

Early microbial biomarkers predictive of the clinical benefits associated with $\mathrm{CR}$ treatment might serve as 
diagnostic tools for identifying overfeeding-related dysbiosis. A recent study showed that some strains have the capability to predict the personal effects of CR treatment [101]. Individuals with a high baseline abundance of $A$. muciniphila before $\mathrm{CR}$ showed improved clinical outcomes after CR, such as improvement in glucose homeostasis, blood lipids, and body composition. The abundance of $A$. muciniphila in these participants was reduced during $\mathrm{CR}$, however, it still remained considerably higher than in those with lower abundance pre-CR [101]. Thus, the levels of $A$. muciniphila could potentially be used for predicting the effect of CR. Another study [21] suggested that Lactobacillus served as a marker of dietary intervention in experimental animal models because the increased relative abundance of Lactobacillus correlated with the lowering of cholesterol and triglycerides shortly after dietary restriction. Additionally, its high abundance persisted after long-term CR treatment.

The calorie restricted diet could be supplemented with some beneficial microbes; thus, the CR impact could be more effective. Some studies [21] have applied a calorie restriction diet with $L$. fermentum CRL1446 and found that such a diet accelerated the microbiota replacement and promoted the presence of the probiotics, Bifidobacterium and Lactobacillus, in the intestine.

\section{Conclusions}

Calorie restriction is a strong environmental force that alters the gut microbiota and global metabolome. Further verification of the direct link between gut microbiota and metabolome as well as, the observation of host phenotypes that correlated with a particular gut microbe composition, metabolite concentrations and physiological parameters would benefit patients at risk for developing metabolic disease. These findings would provide essential metabolic information associated with gut microbial composition under $\mathrm{CR}$ conditions for the consideration of tailored therapeutic treatments to a specific metabolic condition [102-106]. More importantly, the causality between gut microbiota, global metabolism, and CR-induced phenotypes should be evaluated. Strategies have been proposed for identifying causative factors through functional microbiome-wide association studies and mechanistic investigations. Given the potential key role of these factors in mediating the health-promoting actions of $\mathrm{CR}$, improved gut microbiota composition and its resulting metabolome may become a novel biomarker for identifying effective dietary interventions for age-related and metabolic diseases.

\section{Acknowledgements}

This work is supported by the National Natural Science Foundation of China (No. 31500954).

\section{Compliance with ethics guidelines}

Xiaojiao Zheng, Shouli Wang, and Wei Jia declare that they have no conflicts of interest. This manuscript is a review article and does not involve a research protocol requiring approval by the relevant institutional review board or ethics committee.

Open Access This article is distributed under the terms of the Creative Commons Attribution 4.0 International License (http:// creativecommons.org/licenses/by/4.0/), which permits unrestricted use, distribution, and reproduction in any medium, provided the appropriate credit is given to the original author(s) and the source, and a link is provided to the Creative Commons license, which indicates if changes are made.

\section{References}

1. Colman RJ, Anderson RM, Johnson SC, Kastman EK, Kosmatka KJ, Beasley TM, Allison DB, Cruzen C, Simmons HA, Kemnitz JW, Weindruch R. Caloric restriction delays disease onset and mortality in rhesus monkeys. Science 2009; 325(5937): 201-204

2. Fontana L, Klein S. Aging, adiposity, and calorie restriction. JAMA 2007; 297(9): 986-994

3. Zhang C, Li S, Yang L, Huang P, Li W, Wang S, Zhao G, Zhang M, Pang X, Yan Z, Liu Y, Zhao L. Structural modulation of gut microbiota in life-long calorie-restricted mice. Nat Commun 2013; 4(1): 2163

4. Kim KE, Jung Y, Min S, Nam M, Heo RW, Jeon BT, Song DH, Yi CO, Jeong EA, Kim H, Kim J, Jeong SY, Kwak W, Ryu H, Horvath TL, Roh GS, Hwang GS. Caloric restriction of $\mathrm{db} / \mathrm{db}$ mice reverts hepatic steatosis and body weight with divergent hepatic metabolism. Sci Rep 2016; 6(1): 30111

5. Qu B, Halliwell B, Ong CN, Lee BL, Li QT. Caloric restriction prevents oxidative damage induced by the carcinogen clofibrate in mouse liver. FEBS Lett 2000; 473(1): 85-88

6. Longo VD, Mattson MP. Fasting: molecular mechanisms and clinical applications. Cell Metab 2014; 19(2): 181-192

7. Koubova J, Guarente L. How does calorie restriction work? Genes Dev 2003; 17(3): 313-321

8. Wang Y, Lawler D, Larson B, Ramadan Z, Kochhar S, Holmes E, Nicholson JK. Metabonomic investigations of aging and caloric restriction in a life-long dog study. J Proteome Res 2007; 6(5): 1846-1854

9. Kealy RD, Lawler DF, Ballam JM, Mantz SL, Biery DN, Greeley EH, Lust G, Segre M, Smith GK, Stowe HD. Effects of diet restriction on life span and age-related changes in dogs. J Am Vet Med Assoc 2002; 220(9): 1315-1320

10. Masoro EJ. Food restriction in rodents: an evaluation of its role in the study of aging. J Gerontol 1988; 43(3): B59-B64

11. Smilowitz JT, Wiest MM, Watkins SM, Teegarden D, Zemel MB, German JB, Van Loan MD. Lipid metabolism predicts changes in body composition during energy restriction in overweight humans. J Nutr 2009; 139(2): 222-229

12. López-Lluch G, Hunt N, Jones B, Zhu M, Jamieson H, Hilmer S, Cascajo MV, Allard J, Ingram DK, Navas P, de Cabo R. Calorie restriction induces mitochondrial biogenesis and bioenergetic 
efficiency. Proc Natl Acad Sci USA 2006; 103(6): 1768-1773

13. Rezzi S, Martin FP, Shanmuganayagam D, Colman RJ, Nicholson $\mathrm{JK}$, Weindruch R. Metabolic shifts due to long-term caloric restriction revealed in nonhuman primates. Exp Gerontol 2009; 44 (5): 356-362

14. Su HY, Lee HC, Cheng WY, Huang SY. A calorie-restriction diet supplemented with fish oil and high-protein powder is associated with reduced severity of metabolic syndrome in obese women. Eur J Clin Nutr 2015; 69(3): 322-328

15. Schmedes MS, Yde CC, Svensson U, Håkansson J, Baby S, Bertram HC. Impact of a 6-week very low-calorie diet and weight reduction on the serum and fecal metabolome of overweight subjects. Eur Food Res Technol 2015; 240(3): 583-594

16. Kim M, Lee SH, Lee JH. Global metabolic profiling of plasma shows that three-year mild-caloric restriction lessens an age-related increase in sphingomyelin and reduces L-leucine and L-phenylalanine in overweight and obese subjects. Aging Dis 2016; 7(6): $721-733$

17. Guarente L. Mitochondria - a nexus for aging, calorie restriction, and sirtuins? Cell 2008; 132(2): 171-176

18. Zheng X, Zhao A, Xie G, Chi Y, Zhao L, Li H, Wang C, Bao Y, Jia W, Luther M, Su M, Nicholson JK, Jia W. Melamine-induced renal toxicity is mediated by the gut microbiota. Sci Transl Med 2013; 5 (172): 172ra22

19. Goodman AL, Gordon JI. Our unindicted coconspirators: human metabolism from a microbial perspective. Cell Metab 2010; 12(2): $111-116$

20. David LA, Maurice CF, Carmody RN, Gootenberg DB, Button JE, Wolfe BE, Ling AV, Devlin AS, Varma Y, Fischbach MA, Biddinger SB, Dutton RJ, Turnbaugh PJ. Diet rapidly and reproducibly alters the human gut microbiome. Nature 2014; 505 (7484): 559-563

21. Fraumene C, Manghina V, Cadoni E, Marongiu F, Abbondio M, Serra M, Palomba A, Tanca A, Laconi E, Uzzau S. Caloric restriction promotes rapid expansion and long-lasting increase of Lactobacillus in the rat fecal microbiota. Gut Microbes 2018; 9(2): 104-114

22. Wu J, Yang L, Li S, Huang $\mathrm{P}$, Liu Y, Wang Y, Tang $\mathrm{H}$. Metabolomics insights into the modulatory effects of long-term low calorie intake in mice. J Proteome Res 2016; 15(7): 22992308

23. Zheng X, Chen T, Zhao A, Wang X, Xie G, Huang F, Liu J, Zhao Q, Wang S, Wang C, Zhou M, Panee J, He Z, Jia W. The brain metabolome of male rats across the lifespan. Sci Rep 2016; 6(1): 24125

24. Xie G, Zheng X, Qi X, Cao Y, Chi Y, Su M, Ni Y, Qiu Y, Liu Y, Li $\mathrm{H}$, Zhao A, Jia W. Metabonomic evaluation of melamine-induced acute renal toxicity in rats. J Proteome Res 2010; 9(1): 125-133

25. Zheng X, Xie G, Jia W. Metabolomic profiling in colorectal cancer: opportunities for personalized medicine. Per Med 2013; 10 (7): 741-755

26. Xu H, Zheng X, Jia W, Yin S. Chromatography/mass spectrometry-based biomarkers in the field of obstructive sleep apnea. Medicine (Baltimore) 2015; 94(40): e1541

27. Ott B, Skurk T, Hastreiter L, Lagkouvardos I, Fischer S, Büttner J, Kellerer T, Clavel T, Rychlik M, Haller D, Hauner H. Effect of caloric restriction on gut permeability, inflammation markers, and fecal microbiota in obese women. Sci Rep 2017; 7(1): 11955

28. Pataky Z, Genton L, Spahr L, Lazarevic V, Terraz S, Gaïa N, Rubbia-Brandt L, Golay A, Schrenzel J, Pichard C. Impact of hypocaloric hyperproteic diet on gut microbiota in overweight or obese patients with nonalcoholic fatty liver disease: a pilot study. Dig Dis Sci 2016; 61(9): 2721-2731

29. Ruiz A, Cerdó T, Jáuregui R, Pieper DH, Marcos A, Clemente A, García F, Margolles A, Ferrer M, Campoy C, Suárez A. One-year calorie restriction impacts gut microbial composition but not its metabolic performance in obese adolescents. Environ Microbiol 2017; 19(4): 1536-1551

30. Bartley JM, Zhou X, Kuchel GA, Weinstock GM, Haynes L. Impact of age, caloric restriction, and influenza infection on mouse gut microbiome: an exploratory study of the role of age-related microbiome changes on influenza responses. Front Immunol 2017; 8: 1164

31. Henderson AL, Cao WW, Wang RF, Lu MH, Cerniglia CE. The effect of food restriction on the composition of intestinal microflora in rats. Exp Gerontol 1998; 33(3): 239-247

32. Mai V, Colbert LH, Perkins SN, Schatzkin A, Hursting SD. Intestinal microbiota: a potential diet-responsive prevention target in ApcMin mice. Mol Carcinog 2007; 46(1): 42-48

33. Santacruz A, Marcos A, Wärnberg J, Martí A, Martin-Matillas M, Campoy C, Moreno LA, Veiga O, Redondo-Figuero C, Garagorri JM, Azcona C, Delgado M, García-Fuentes M, Collado MC, Sanz Y; EVASYON Study Group. Interplay between weight loss and gut microbiota composition in overweight adolescents. Obesity (Silver Spring) 2009; 17(10): 1906-1915

34. Damms-Machado A, Mitra S, Schollenberger AE, Kramer KM, Meile T, Königsrainer A, Huson DH, Bischoff SC. Effects of surgical and dietary weight loss therapy for obesity on gut microbiota composition and nutrient absorption. BioMed Res Int 2015; 2015: 806248

35. Russo M, Fabersani E, Abeijón-Mukdsi MC, Ross R, Fontana C, Benítez-Páez A, Gauffin-Cano P, Medina RB. Lactobacillus fermentum CRL1446 ameliorates oxidative and metabolic parameters by increasing intestinal feruloyl esterase activity and modulating microbiota in caloric-restricted mice. Nutrients 2016; 8 (7): E415

36. Bernardeau M, Guguen M, Vernoux JP. Beneficial lactobacilli in food and feed: long-term use, biodiversity and proposals for specific and realistic safety assessments. FEMS Microbiol Rev 2006; 30(4): 487-513

37. Zareie M, Johnson-Henry K, Jury J, Yang PC, Ngan BY, McKay DM, Soderholm JD, Perdue MH, Sherman PM. Probiotics prevent bacterial translocation and improve intestinal barrier function in rats following chronic psychological stress. Gut 2006; 55(11): $1553-1560$

38. Sun J, Buys N. Effects of probiotics consumption on lowering lipids and CVD risk factors: a systematic review and meta-analysis of randomized controlled trials. Ann Med 2015; 47(6): 430-440

39. Zhang C, Zhang M, Wang S, Han R, Cao Y, Hua W, Mao Y, Zhang $\mathrm{X}$, Pang X, Wei C, Zhao G, Chen Y, Zhao L. Interactions between gut microbiota, host genetics and diet relevant to development of metabolic syndromes in mice. ISME J 2010; 4(2): 232-241

40. Price LB, Liu CM, Melendez JH, Frankel YM, Engelthaler D, Aziz M, Bowers J, Rattray R, Ravel J, Kingsley C, Keim PS, Lazarus 
GS, Zenilman JM. Community analysis of chronic wound bacteria using 16S rRNA gene-based pyrosequencing: impact of diabetes and antibiotics on chronic wound microbiota. PLoS One 2009; 4 (7): e6462

41. Kuehbacher T, Rehman A, Lepage P, Hellmig S, Fölsch UR, Schreiber S, Ott SJ. Intestinal TM7 bacterial phylogenies in active inflammatory bowel disease. J Med Microbiol 2008; 57(Pt 12): $1569-1576$

42. Zweigner J, Schumann RR, Weber JR. The role of lipopolysaccharide-binding protein in modulating the innate immune response. Microbes Infect 2006; 8(3): 946-952

43. Cani PD, Amar J, Iglesias MA, Poggi M, Knauf C, Bastelica D, Neyrinck AM, Fava F, Tuohy KM, Chabo C, Waget A, Delmée E, Cousin B, Sulpice T, Chamontin B, Ferrières J, Tanti JF, Gibson GR, Casteilla L, Delzenne NM, Alessi MC, Burcelin R. Metabolic endotoxemia initiates obesity and insulin resistance. Diabetes 2007; 56(7): 1761-1772

44. Brahe LK, Astrup A, Larsen LH. Is butyrate the link between diet, intestinal microbiota and obesity-related metabolic diseases? Obes Rev 2013; 14(12): 950-959

45. Canfora EE, Jocken JW, Blaak EE. Short-chain fatty acids in control of body weight and insulin sensitivity. Nat Rev Endocrinol 2015; 11(10): 577-591

46. Endo H, Niioka M, Kobayashi N, Tanaka M, Watanabe $T$. Butyrate-producing probiotics reduce nonalcoholic fatty liver disease progression in rats: new insight into the probiotics for the gut-liver axis. PLoS One 2013; 8(5): e63388

47. Schwiertz A, Taras D, Schäfer K, Beijer S, Bos NA, Donus C, Hardt PD. Microbiota and SCFA in lean and overweight healthy subjects. Obesity (Silver Spring) 2010; 18(1): 190-195

48. Selman C, Kerrison ND, Cooray A, Piper MD, Lingard SJ, Barton RH, Schuster EF, Blanc E, Gems D, Nicholson JK, Thornton JM, Partridge L, Withers DJ. Coordinated multitissue transcriptional and plasma metabonomic profiles following acute caloric restriction in mice. Physiol Genomics 2006; 27(3): 187-200

49. Richards SE, Wang Y, Lawler D, Kochhar S, Holmes E, Lindon JC, Nicholson JK. Self-modeling curve resolution recovery of temporal metabolite signal modulation in NMR spectroscopic data sets: application to a life-long caloric restriction study in dogs. Anal Chem 2008; 80(13): 4876-4885

50. Margolis LM, Rivas DA, Ezzyat Y, Gaffney-Stomberg E, Young AJ, McClung JP, Fielding RA, Pasiakos SM. Calorie restricted high protein diets downregulate lipogenesis and lower intrahepatic triglyceride concentrations in male rats. Nutrients 2016; 8(9): E571

51. Krebs M, Krssak M, Bernroider E, Anderwald C, Brehm A, Meyerspeer M, Nowotny P, Roth E, Waldhäusl W, Roden M. Mechanism of amino acid-induced skeletal muscle insulin resistance in humans. Diabetes 2002; 51(3): 599-605

52. Solon-Biet SM, Mitchell SJ, Coogan SC, Cogger VC, Gokarn R, McMahon AC, Raubenheimer D, de Cabo R, Simpson SJ, Le Couteur DG. Dietary protein to carbohydrate ratio and caloric restriction: comparing metabolic outcomes in mice. Cell Reports 2015; 11(10): 1529-1534

53. Huffman KM, Shah SH, Stevens RD, Bain JR, Muehlbauer M, Slentz CA, Tanner CJ, Kuchibhatla M, Houmard JA, Newgard CB, Kraus WE. Relationships between circulating metabolic intermediates and insulin action in overweight to obese, inactive men and women. Diabetes Care 2009; 32(9): 1678-1683

54. Shaham O, Wei R, Wang TJ, Ricciardi C, Lewis GD, Vasan RS, Carr SA, Thadhani R, Gerszten RE, Mootha VK. Metabolic profiling of the human response to a glucose challenge reveals distinct axes of insulin sensitivity. Mol Syst Biol 2008; 4: 214

55. Walsh MC, Brennan L, Malthouse JP, Roche HM, Gibney MJ. Effect of acute dietary standardization on the urinary, plasma, and salivary metabolomic profiles of healthy humans. Am J Clin Nutr 2006; 84(3): 531-539

56. Mellert W, Kapp M, Strauss V, Wiemer J, Kamp H, Walk T, Looser R, Prokoudine A, Fabian E, Krennrich G, Herold M, van Ravenzwaay B. Nutritional impact on the plasma metabolome of rats. Toxicol Lett 2011; 207(2): 173-181

57. Simón E, Portillo MP, Fernández-Quintela A, Zulet MA, Martínez JA, Del Barrio AS. Responses to dietary macronutrient distribution of overweight rats under restricted feeding. Ann Nutr Metab 2002; 46(1): 24-31

58. Selmer T, Andrei PI. p-Hydroxyphenylacetate decarboxylase from Clostridium difficile. A novel glycyl radical enzyme catalysing the formation of p-cresol. Eur J Biochem 2001; 268(5): 1363-1372

59. Lees HJ, Swann JR, Wilson ID, Nicholson JK, Holmes E. Hippurate: the natural history of a mammalian-microbial cometabolite. J Proteome Res 2013; 12(4): 1527-1546

60. Jové M, Naudí A, Ramírez-Núñez O, Portero-Otín M, Selman C, Withers DJ, Pamplona R. Caloric restriction reveals a metabolomic and lipidomic signature in liver of male mice. Aging Cell 2014; 13 (5): 828-837

61. Zheng H, Lorenzen JK, Astrup A, Larsen LH, Yde CC, Clausen MR, Bertram HC. Metabolic effects of a 24-week energy-restricted intervention combined with low or high dairy intake in overweight women: an NMR-based metabolomics investigation. Nutrients 2016; 8(3): 108

62. Nicholson JK, Holmes E, Kinross J, Burcelin R, Gibson G, Jia W, Pettersson S. Host-gut microbiota metabolic interactions. Science 2012; 336(6086): 1262-1267

63. Zheng X, Xie G, Zhao A, Zhao L, Yao C, Chiu NH, Zhou Z, Bao Y, Jia W, Nicholson JK, Jia W. The footprints of gut microbialmammalian co-metabolism. J Proteome Res 2011; 10(12): 55125522

64. Williams RE, Lenz EM, Lowden JS, Rantalainen M, Wilson ID. The metabonomics of aging and development in the rat: an investigation into the effect of age on the profile of endogenous metabolites in the urine of male rats using $1 \mathrm{H}$ NMR and HPLCTOF MS. Mol Biosyst 2005; 1(2): 166-175

65. Schnackenberg LK, Sun J, Espandiari P, Holland RD, Hanig J, Beger RD. Metabonomics evaluations of age-related changes in the urinary compositions of male Sprague Dawley rats and effects of data normalization methods on statistical and quantitative analysis. BMC Bioinformatics 2007; 8(Suppl 7): S3

66. Hennebelle M, Roy M, St-Pierre V, Courchesne-Loyer A, Fortier M, Bouzier-Sore AK, Gallis JL, Beauvieux MC, Cunnane SC. Energy restriction does not prevent insulin resistance but does prevent liver steatosis in aging rats on a Western-style diet. Nutrition 2015; 31(3): 523-530

67. Nestor G, Eriksson J, Sandström C, Malmlöf K. Nuclear magnetic resonance-based blood metabolic profiles of rats exposed to shortterm caloric restriction. Anal Lett 2015; 48(16): 2613-2625 
68. al-Waiz M, Mikov M, Mitchell SC, Smith RL. The exogenous origin of trimethylamine in the mouse. Metabolism 1992; 41(2): $135-136$

69. De Guzman JM, Ku G, Fahey R, Youm YH, Kass I, Ingram DK, Dixit VD, Kheterpal I. Chronic caloric restriction partially protects against age-related alteration in serum metabolome. Age (Dordr) 2013; 35(4): 1091-1104

70. Zhang Y, Yan S, Gao X, Dai W, Liu S, Jin H, Zhang W, Mei C. Metabonomic investigation on the protective effects of rosiglitazone and caloric restriction for renal senescence in a rat model. Aging Clin Exp Res 2012; 24(5): 430-438

71. Meidenbauer JJ, Ta N, Seyfried TN. Influence of a ketogenic diet, fish-oil, and calorie restriction on plasma metabolites and lipids in C57BL/6J mice. Nutr Metab (Lond) 2014; 11(1): 23

72. Malandrucco I, Pasqualetti P, Giordani I, Manfellotto D, De Marco F, Alegiani F, Sidoti AM, Picconi F, Di Flaviani A, Frajese G, Bonadonna RC, Frontoni S. Very-low-calorie diet: a quick therapeutic tool to improve $\beta$ cell function in morbidly obese patients with type 2 diabetes. Am J Clin Nutr 2012; 95(3): 609-613

73. Szapary PO, Rader DJ. The triglyceride-high-density lipoprotein axis: an important target of therapy? Am Heart J 2004; 148(2): 211-221

74. Cazzola R, Rondanelli M, Trotti R, Cestaro B. Effects of weight loss on erythrocyte membrane composition and fluidity in overweight and moderately obese women. J Nutr Biochem 2011; 22(4): 388-392

75. Samad F, Hester KD, Yang G, Hannun YA, Bielawski J. Altered adipose and plasma sphingolipid metabolism in obesity: a potential mechanism for cardiovascular and metabolic risk. Diabetes 2006; 55(9): 2579-2587

76. Weir JM, Wong G, Barlow CK, Greeve MA, Kowalczyk A, Almasy L, Comuzzie AG, Mahaney MC, Jowett JB, Shaw J, Curran JE, Blangero J, Meikle PJ. Plasma lipid profiling in a large population-based cohort. J Lipid Res 2013; 54(10): 2898-2908

77. Singh R, Kaushik S, Wang Y, Xiang Y, Novak I, Komatsu M, Tanaka K, Cuervo AM, Czaja MJ. Autophagy regulates lipid metabolism. Nature 2009; 458(7242): 1131-1135

78. Eckel RH, Grundy SM, Zimmet PZ. The metabolic syndrome. Lancet 2005; 365(9468): 1415-1428

79. Ni Y, Zhao L, Yu H, Ma X, Bao Y, Rajani C, Loo LW, Shvetsov YB, Yu H, Chen T, Zhang Y, Wang C, Hu C, Su M, Xie G, Zhao A, Jia W, Jia W. Circulating unsaturated fatty acids delineate the metabolic status of obese individuals. EBioMedicine 2015; 2(10): $1513-1522$

80. Wijeyesekera A, Selman C, Barton RH, Holmes E, Nicholson JK, Withers DJ. Metabotyping of long-lived mice using $1 \mathrm{H}$ NMR spectroscopy. J Proteome Res 2012; 11(4): 2224-2235

81. Javitt NB. Bile acid synthesis from cholesterol: regulatory and auxiliary pathways. FASEB J 1994; 8(15): 1308-1311

82. Jia W, Xie G, Jia W. Bile acid-microbiota crosstalk in gastrointestinal inflammation and carcinogenesis. Nat Rev Gastroenterol Hepatol 2017; 15(2): 111-128

83. Thomas C, Pellicciari R, Pruzanski M, Auwerx J, Schoonjans K. Targeting bile-acid signalling for metabolic diseases. Nat Rev Drug Discov 2008; 7(8): 678-693

84. Fu ZD, Klaassen CD. Increased bile acids in enterohepatic circulation by short-term calorie restriction in male mice. Toxicol
Appl Pharmacol 2013; 273(3): 680-690

85. Straniero S, Rosqvist F, Edholm D, Ahlström H, Kullberg J, Sundbom M, Risérus U, Rudling M. Acute caloric restriction counteracts hepatic bile acid and cholesterol deficiency in morbid obesity. J Intern Med 2017; 281(5): 507-517

86. Green CL, Mitchell SE, Derous D, Wang Y, Chen L, Han JJ, Promislow DEL, Lusseau D, Douglas A, Speakman JR. The effects of graded levels of calorie restriction: IX. Global metabolomic screen reveals modulation of carnitines, sphingolipids and bile acids in the liver of C57BL/6 mice. Aging Cell 2017; 16(3): 529540

87. Hatori M, Vollmers C, Zarrinpar A, DiTacchio L, Bushong EA, Gill S, Leblanc M, Chaix A, Joens M, Fitzpatrick JA, Ellisman $\mathrm{MH}$, Panda S. Time-restricted feeding without reducing caloric intake prevents metabolic diseases in mice fed a high-fat diet. Cell Metab 2012; 15(6): 848-860

88. Watanabe M, Houten SM, Mataki C, Christoffolete MA, Kim BW, Sato H, Messaddeq N, Harney JW, Ezaki O, Kodama T, Schoonjans K, Bianco AC, Auwerx J. Bile acids induce energy expenditure by promoting intracellular thyroid hormone activation. Nature 2006; 439(7075): 484-489

89. Ferbeyre G. Bile acids in the fountain of youth. Aging (Albany NY) 2010; 2(7): 383-384

90. MacDonald M, Neufeldt N, Park BN, Berger M, Ruderman N. Alanine metabolism and gluconeogenesis in the rat. Am J Physiol 1976; 231(2): 619-626

91. Lee CK, Klopp RG, Weindruch R, Prolla TA. Gene expression profile of aging and its retardation by caloric restriction. Science 1999; 285(5432): 1390-1393

92. Lee CK, Weindruch R, Prolla TA. Gene-expression profile of the ageing brain in mice. Nat Genet 2000; 25(3): 294-297

93. Wu C, Kang JE, Peng LJ, Li H, Khan SA, Hillard CJ, Okar DA, Lange AJ. Enhancing hepatic glycolysis reduces obesity: differential effects on lipogenesis depend on site of glycolytic modulation. Cell Metab 2005; 2(2): 131-140

94. Lee CH, Olson P, Hevener A, Mehl I, Chong LW, Olefsky JM, Gonzalez FJ, Ham J, Kang H, Peters JM, Evans RM. PPAR $\delta$ regulates glucose metabolism and insulin sensitivity. Proc Natl Acad Sci USA 2006; 103(9): 3444-3449

95. Gu Y, Zhao A, Huang F, Zhang Y, Liu J, Wang C, Jia W, Xie G, Jia W. Very low carbohydrate diet significantly alters the serum metabolic profiles in obese subjects. J Proteome Res 2013; 12(12): $5801-5811$

96. Newgard CB, An J, Bain JR, Muehlbauer MJ, Stevens RD, Lien LF, Haqq AM, Shah SH, Arlotto M, Slentz CA, Rochon J, Gallup D, Ilkayeva O, Wenner BR, Yancy WS Jr, Eisenson H, Musante G, Surwit RS, Millington DS, Butler MD, Svetkey LP. A branchedchain amino acid-related metabolic signature that differentiates obese and lean humans and contributes to insulin resistance. Cell Metab 2009; 9(4): 311-326

97. Shah SH, Crosslin DR, Haynes CS, Nelson S, Turer CB, Stevens $\mathrm{RD}$, Muehlbauer MJ, Wenner BR, Bain JR, Laferrère B, Gorroochurn P, Teixeira J, Brantley PJ, Stevens VJ, Hollis JF, Appel LJ, Lien LF, Batch B, Newgard CB, Svetkey LP. Branchedchain amino acid levels are associated with improvement in insulin resistance with weight loss. Diabetologia 2012; 55(2): 321-330

98. Nilsson M, Holst JJ, Björck IM. Metabolic effects of amino acid 
mixtures and whey protein in healthy subjects: studies using glucose-equivalent drinks. Am J Clin Nutr 2007; 85(4): 996-1004

99. Tavernarakis N, Driscoll M. Caloric restriction and lifespan: a role for protein turnover? Mech Ageing Dev 2002; 123(2-3): 215-229

100. Ingram DK, Young J, Mattison JA. Calorie restriction in nonhuman primates: assessing effects on brain and behavioral aging. Neuroscience 2007; 145(4): 1359-1364

101. Dao MC, Everard A, Aron-Wisnewsky J, Sokolovska N, Prifti E, Verger EO, Kayser BD, Levenez F, Chilloux J, Hoyles L; MICROObes Consortium, Dumas ME, Rizkalla SW, Doré J, Cani PD, Clément K. Akkermansia muciniphila and improved metabolic health during a dietary intervention in obesity: relationship with gut microbiome richness and ecology. Gut 2016; 65(3): 426-436

102. Griffin NW, Ahern PP, Cheng J, Heath AC, Ilkayeva O, Newgard CB, Fontana L, Gordon JI. Prior dietary practices and connections to a human gut microbial metacommunity alter responses to diet interventions. Cell Host Microbe 2017; 21(1): 84-96

103. Le Chatelier E, Nielsen T, Qin J, Prifti E, Hildebrand F, Falony G, Almeida M, Arumugam M, Batto JM, Kennedy S, Leonard P, Li J, Burgdorf K, Grarup N, Jørgensen T, Brandslund I, Nielsen HB, Juncker AS, Bertalan M, Levenez F, Pons N, Rasmussen S, Sunagawa S, Tap J, Tims S, Zoetendal EG, Brunak S, Clément K,
Doré J, Kleerebezem M, Kristiansen K, Renault P, SicheritzPonten T, de Vos WM, Zucker JD, Raes J, Hansen T; MetaHIT consortium, Bork P, Wang J, Ehrlich SD, Pedersen O. Richness of human gut microbiome correlates with metabolic markers. Nature 2013; 500(7464): 541-546

104. Cotillard A, Kennedy SP, Kong LC, Prifti E, Pons N, Le Chatelier E, Almeida M, Quinquis B, Levenez F, Galleron N, Gougis S, Rizkalla S, Batto JM, Renault P; ANR MicroObes consortium, Doré J, Zucker JD, Clément K, Ehrlich SD. Dietary intervention impact on gut microbial gene richness. Nature 2013; 500(7464): 585-588

105. Stefka AT, Feehley T, Tripathi P, Qiu J, McCoy K, Mazmanian SK, Tjota MY, Seo GY, Cao S, Theriault BR, Antonopoulos DA, Zhou L, Chang EB, Fu YX, Nagler CR. Commensal bacteria protect against food allergen sensitization. Proc Natl Acad Sci USA 2014; 111(36): 13145-13150

106. Zeevi D, Korem T, Zmora N, Israeli D, Rothschild D, Weinberger A, Ben-Yacov O, Lador D, Avnit-Sagi T, Lotan-Pompan M, Suez J, Mahdi JA, Matot E, Malka G, Kosower N, Rein M, ZilbermanSchapira G, Dohnalová L, Pevsner-Fischer M, Bikovsky R, Halpern Z, Elinav E, Segal E. Personalized nutrition by prediction of glycemic responses. Cell 2015; 163(5): 1079-1094 